\title{
Stationary Filter Filtration
}

National Cancer Institute

\section{Source}

National Cancer Institute. Stationary Filter Filtration. NCI Thesaurus. Code C113002.

The use of an immobilized filter unit to purify a slurry. 